\title{
Tracheobronchial remnant as a cause of oesophageal stricture in children - case report and review of the literature
}

\author{
Marek Szymczak', Agata Trypens'1, Grzegorz Kowalewski', Dariusz Polnik', Dorota Broniszczak', \\ Małgorzata Łyszkowska', Dorota Majak², Marek Woynarowski' ${ }^{3}$, Maciej Pronicki' ${ }^{4}$ Piotr Kaliciński ${ }^{1}$ \\ 'Department of Paediatric Surgery and Organ Transplantation, Children's Memorial Health Institute, Warsaw, Poland \\ ${ }^{2}$ Department of Diagnostic Imaging, Children's Memorial Health Institute, Warsaw, Poland \\ ${ }^{3}$ Department of Gastroenterology, Hepatology, Nutrition Disorders, and Paediatrics, Children's Memorial Health Institute, \\ Warsaw, Poland \\ ${ }^{4}$ Department of Pathology, Children's Memorial Health Institute, Warsaw, Poland
}

\section{ABSTRACT}

Tracheobronchial remnant (TBR), one of the causes of congenital oesophageal stenosis (COS), is a rare anomaly, the treatment of which is hampered by the lack of well-established therapeutic strategies. A definite diagnosis of TBR can be made only by histopathological examination of the resected segment. A 10-month-old girl was admitted to a district hospital due to dysphagia, intolerance of solid food, and regurgitation. The patient was referred to our hospital for continuation of the treatment. She underwent a laparotomy, segmental resection of the oesophageal narrowing, end-to-end anastomosis, and anterior fundoplication. Surgical excision of the stricture is the only effective treatment of a patient with TBR.

KEY WORDS:

oesophageal stenosis, tracheobronchial remnant, congenital oesophageal stricture.

\section{INTRODUCTION}

Congenital oesophageal stenosis (COS) is a rare anomaly in children with the incidence estimated at $1: 25,000-50,000$ live births [1]. COS may have various aetiologies, and its association with the other anomalies ranges from $17 \%$ to $33 \%$ [2]. COS is recognised most often in Japan, as shown by numerous publications from this country [3]. Nihoul-Fekete classified COS in to three histologic types: tracheobronchial remnant (TBR), fibromuscular thickening (FM), and membranous web (MW) [4-6]. Preoperative diagnosis may be difficult, and there is no unified therapeutic strategy. The authors present a case of a patient with oesophageal stenosis due to TBR.

\section{CASE REPORT}

A 10-month-old girl was admitted to a district hospital due to dysphagia and regurgitation. The symptoms were observed since her birth and gradually increased in severity. With introduction of diversified food, the patient started to have difficulties swallowing solids with episodes of choking. Moreover, she could only tolerate small portions of semi-fluid food.

\section{ADDRESS FOR CORRESPONDENCE:}

Agata Trypens, Department of Paediatric Surgery and Organ Transplantation, Children's Memorial

Health Institute, 20 Dzieci Polskich Ave, 04-730 Warsaw, Poland, ORCID: 0000-0002-1210-5390,

e-mail: agatatrypens@gmail.com 


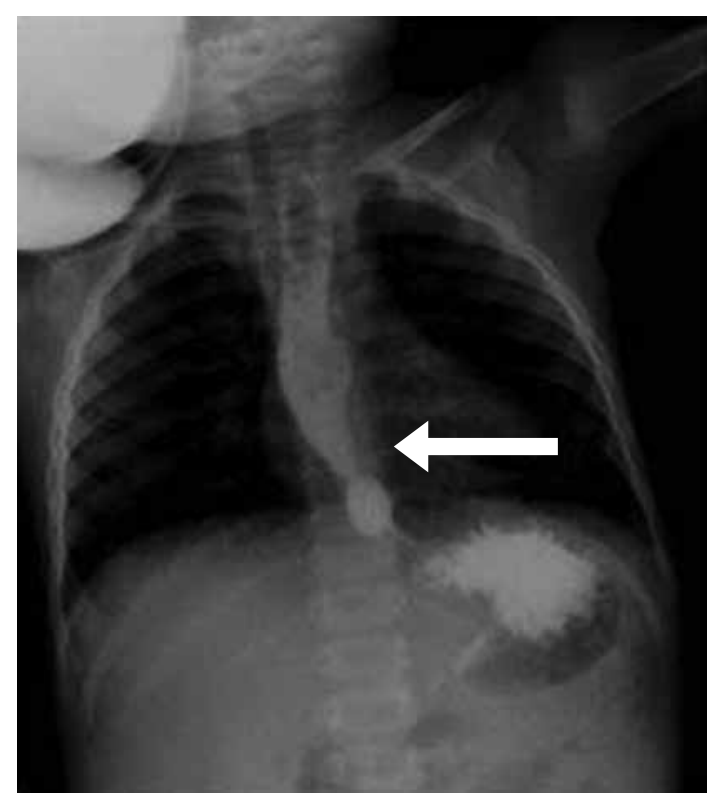

FIGURE 1. Barium oesophagogram in a patient with TBR - the arrow marks abrupt stenosis in the distal part of the oesophagus

Initially a barium oesophagography was performed. The investigation revealed a hiatal hernia $12 \mathrm{~mm}$ in diameter; the oesophagus above the hernia was dilatated to $14 \mathrm{~mm}$ with barium stasis, and the cardia was described as narrow and rigid (Fig. 1). Because the oesophageal stricture was suspected to be associated with oesophagitis, proton-pump inhibitors (PPIs) were included in the treatment. Manometric examination was impossible because the patient presented with severe gag reflex. Esophagoscopy showed normal upper $2 / 3$ of the oesophagus, but a $1-1.5-\mathrm{cm}$-long rigid stricture was found in the distal third of the oesophagus. The diameter of the stricture was about $3 \mathrm{~mm}$. What drew attention was that the endoscope $2.7 \mathrm{~mm}$ springed on the rigid narrowing, and thus the balloon dilatation was withdrawn.

The patient was then referred to our hospital and underwent interdisciplinary gastroenterological, radiological, and surgical consultation.
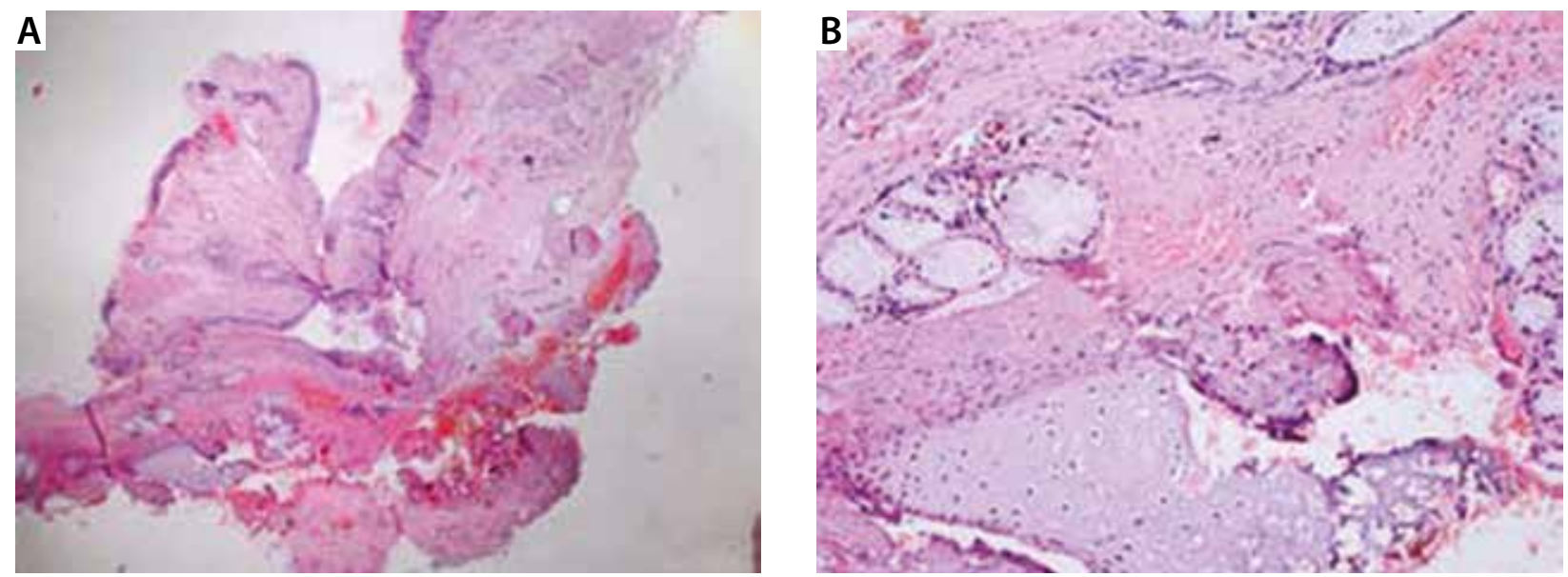

FIGURE 2. Tracheobronchial remnant - histopathological examination. Fragments of the airway wall with paraepidermoid epithelium and cartilaginous elements 

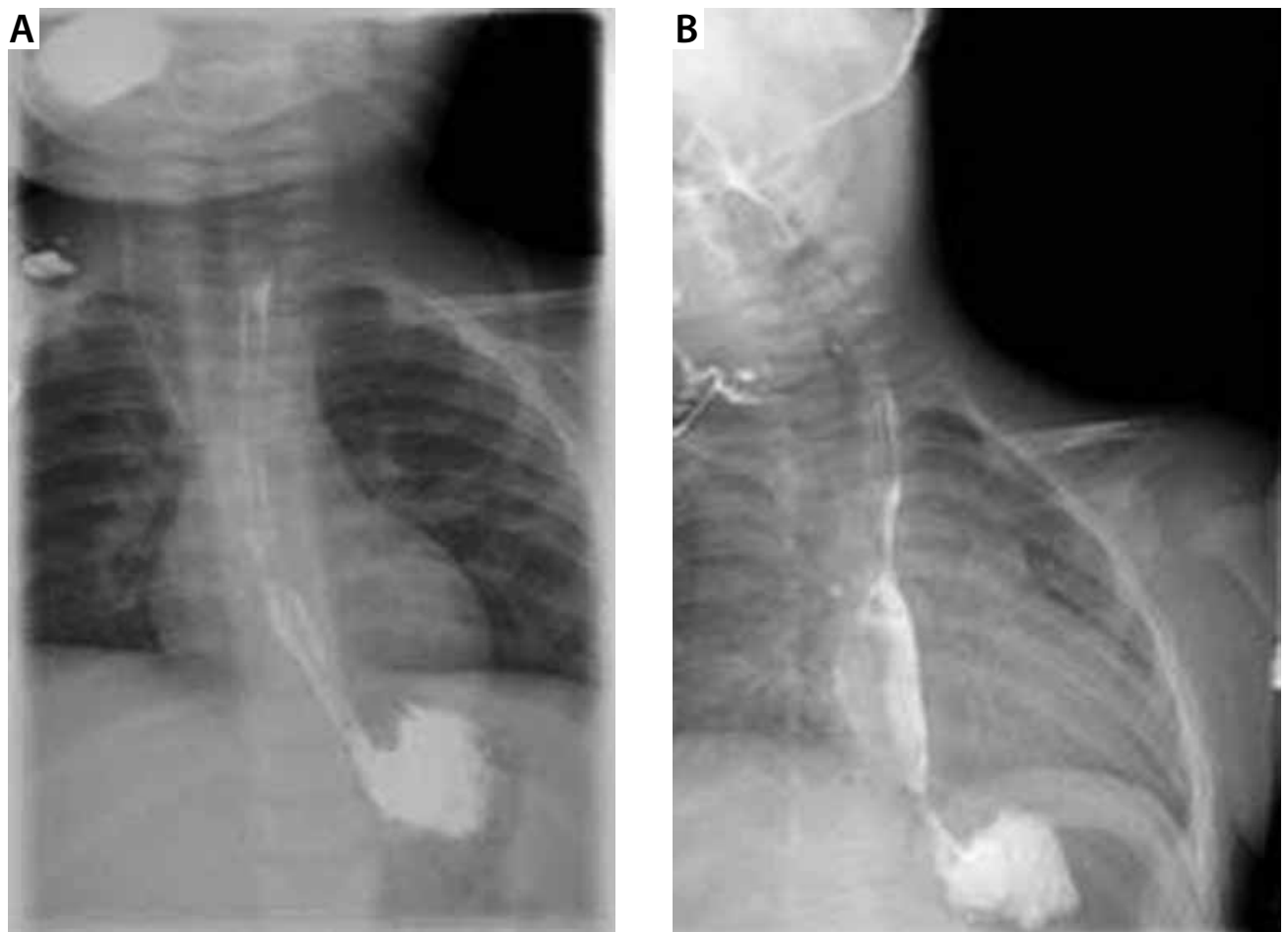

FIGURE 3. Oesophagography in a patient with TBR after oesophageal resection and partial fundoplication. A) one week after surgery - smooth contrast transition to the stomach, B) three weeks after surgery - slight narrowing in oesophageal anastomosis

patient remains asymptomatic, eats normally, and has gained weight.

\section{DISCUSSION}

Tracheobronchial remnant is a very rare congenital anomaly, and therefore it may cause diagnostic and therapeutic difficulties. It was first described by Frey and Duschel in 1936 [7]. TBR is defined as abnormal presence of a ring of tracheal or bronchial cartilage in the wall of the distal oesophagus [8]. It is caused by abnormal separation in the embryonic period (around the $25^{\text {th }}$ embryonic day) of the respiratory system from the foregut and can be associated with oesophageal atresia and tracheoesophageal fistula $[5,9]$. The most common defect accompanying TBR is oesophageal atresia with or without fistula [9]. TBR might contain respiratory epithelium, bronchial glands, cartilage, or lymphatic tissue in the submucosa or muscularis propria and occur in the abdominal part of the oesophagus [10].

The presented case is, to our knowledge, the first described TBR case in Poland. The majority of available literature consists of case reports. The largest group of patients with TBR was described by Kim from South Korea -29 children [11]. TBR can also be diagnosed in adult patients [12].

The diagnostic procedures are usually performed due to complaints of dysphagia, regurgitations, and difficulty in feeding or even in swallowing saliva. Dysphagia occurs usually after introduction of solid food; however, in the case of TBR it may occur in later infancy $[13,14]$. The

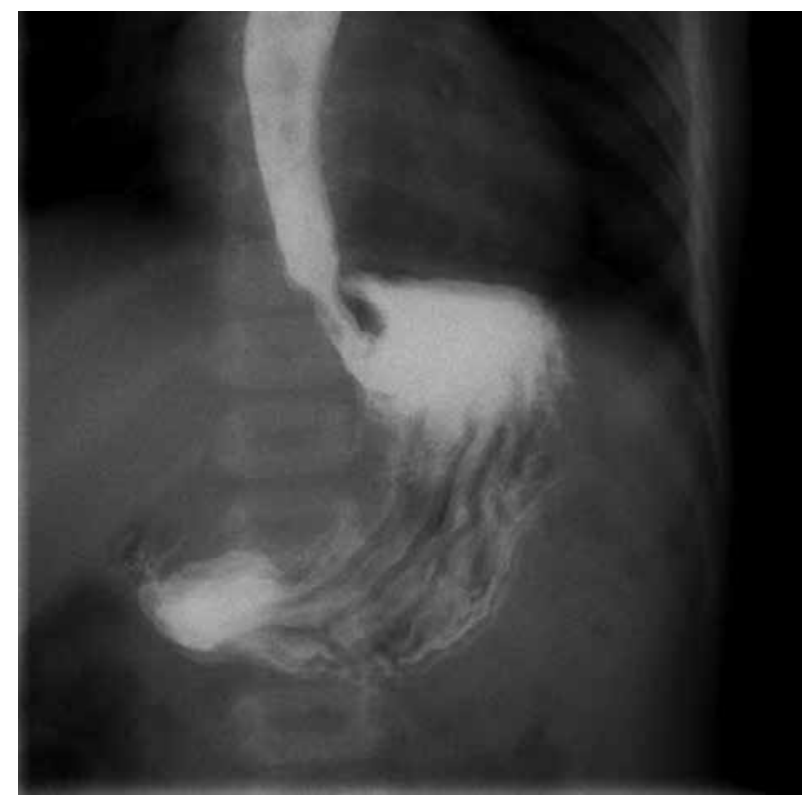

FIGURE 4. Oesophagography in a patient three years after the surgery - smooth barium passage

diagnosis of TBR is often delayed. Symptoms are similar to those occurring in oesophageal stenosis caused by achalasia, reflux oesophagitis, and other acquired causes of oesophageal strictures. The diagnosis of TBR may be suspected based on examinations such as oesophagoscopy and oesophagography, which remain the primary diagnostic tools. Oesophageal manometry test and endoscopic ultrasonography (EUS) are also useful in the diagnosis of COS and its differentiation $[9,13,15]$. A barium 
TABLE 1. Series of pediatric patients with tracheobronchial remnant: review of the literature

\begin{tabular}{|l|c|c|c|}
\hline Author & $\begin{array}{c}\text { Year of } \\
\text { publication }\end{array}$ & $\begin{array}{c}\text { No. of } \\
\text { patients }\end{array}$ & $\begin{array}{c}\text { Methods } \\
\text { of operation }\end{array}$ \\
\hline $\begin{array}{l}\text { Nihoul-Fekete } \\
\text { et al. }\end{array}$ & 1987 & 4 & Segmental resection \\
\hline Olguner et al. & 1997 & 1 & Segmental resection \\
\hline Ramesh et al. & 2001 & 1 & Segmental resection \\
\hline Usui et al. & 2002 & 1 & Segmental resection \\
\hline Amae et al. & 2003 & 6 & Segmental resection \\
\hline Maeda et al. & 2004 & 1 & Circular myectomy \\
\hline Zhao et al. & 2004 & 3 & Segmental resection \\
\hline Saito et al. & 2008 & 1 & Circular myectomy \\
\hline $\begin{array}{l}\text { Nemolato } \\
\text { et al. }\end{array}$ & 2008 & 1 & Segmental resection \\
\hline $\begin{array}{l}\text { Urushihara } \\
\text { et al. }\end{array}$ & 2013 & 2 & Segmental resection \\
\hline Sagna et al. & 2014 & 3 & Segmental resection \\
\hline Mai et al. & 2015 & 1 & Segmental resection \\
\hline Kim et al. & 2017 & 29 & Segmental resection \\
\hline $\begin{array}{l}\text { Presented } \\
\text { study }\end{array}$ & 2018 & 1 & Segmental resection \\
\hline
\end{tabular}

oesophagogram identifies tapered oesophageal stenosis with proximal dilatation in the lower part of the oesophagus. The oesophagoscopy reveals an annular rigid stricture, which is not prone to balloon dilatation but is easily performed in oesophageal achalasia. The manometric examination may exclude the disturbances of the basic pressure of the lower oesophageal sphincter, characteristic for achalasia. Definitive diagnosis can only be made after histopathological examination.

A high-frequency catheter probe EUS may be useful in the evaluation of mucosal and submucosal lesions of the oesophagus [15].

There is no uniform treatment strategy in patients with CES. Conservative procedures, such as balloon dilatation or bouginage, may be effective in cases of stenosis caused by FM or MW, but patients with TBR do not respond to such treatment and require surgical removal of the tracheal remnant through circular myectomy - enucleation or segmental resection of the stenotic segment and oesophageal anastomosis $[3-5,13,14]$. Reports from other centres are presented in Table 1 . The length of the stenosis caused by TBR is usually about $1-2 \mathrm{~cm}$, as presented in our patient [5]. We confirmed the extent of oesophageal stenosis and determined the resection with the assistance of intraoperative endoscopy. This procedure was also used and recommended by other authors [4].

A surgical treatment approach via laparotomy is commonly used, but thoracotomy can also be performed [16]. Segmental oesophageal resection and anastomosis require mobilisation of the upper end of the oesophagus to lim- it the tension as much as possible. Currently, minimally invasive methods may be used for partial oesophageal resection [16]. A laparoscopic or thoracoscopic approach can be performed even in small children. Urushihara described two cases of COS in children aged 23 months and 13 months (one with TBR), in whom he used laparoscopy and thoracoscopy to remove oesophageal stenosis [16]. Shortening of the oesophagus predisposes to gastroesophageal reflux (GER), therefore most authors carry out segmental oesophageal resection and end-toend anastomosis together with fundoplication. In the case of circular myectomy, the most common complication is perforation of the oesophagus, fundoplication is not always performed during this surgical approach.

\section{CONCLUSIONS}

In summary, in the case of swallowing disorders in young children and after exclusion of other causes such as post-inflammatory stenosis, oesophageal reflux, or oesophageal achalasia, the possibility of occurrence of TBR should be considered. In these patients, oesophageal dilatations are impossible to perform and may lead to its perforation. Children with TBR should be operated in centres with long experience in oesophageal surgery. Surgical resection of stenotic distal oesophagus is recommended in patients with TBR, but in some cases excision of the tracheobronchial remnant through myectomy may be possible. Histopathological examination is necessary to confirm the diagnosis. Postoperative complications are uncommon, but patients should be followed up closely [9]. If post-operative stenosis in the anastomosis site is diagnosed, endoscopic examination and balloon dilatation should be performed.

\section{DISCLOSURE}

The authors declare no conflict of interest.

\section{REFERENCES}

1. Bluestone CD, Kerry R, Sieber WK. Congenital esophageal stenosis. Laryngoscope 1969; 79: 1095-103.

2. Rowe MI, O’Neill JA, Grosfeld JL, et al. Essentials of Pediatric Surgery. Mosby Year-Book, St Louis, MO 1995; 959-961.

3. Amae S, Nio M, Kamiyama T, et al. Clinical characteristics and management of congenital esophageal stenosis: a report on 14 cases. J Pediatr Surg 2003; 38: 565-570.

4. Takamizawa S, Tsugawa C, Mouri N, et al. Congenital esophageal stenosis: Therapeutic strategy based on etiology. J Pediatr Surg 2002; 37: 197-201.

5. Maeda K, Hisamatsu C, Hasegawa T, et al. Circular myectomy for the treatment of congenital esophageal stenosis owing to tracheobronchial remnant. J Pediatr Surg 2004; 39: 1765-1768.

6. Ramesh JC, Ramanujam TM, Jayaram G. Congenital esophageal stenosis: report of three cases, literature review, and a proposed classification. Pediatr Surg Int 2001; 17: 188-192. 
7. Park BG, Rho MS, Lee SY, et al. Congenital Esophageal Stenosis due to Tracheobronchial Remnants: A case report. Korean J Pathol 1994; 28: 442-444.

8. Sagna A, Fall I, Ly A, Fall M. Congenital esophagostenosis due to tracheobronchial remnant in infant: 3 cases report. J Pediatr Surg Case Rep 2014; 2: 166-169.

9. Zhaoa LL, Hsieha WS, Hsub WM. Congenital esophageal stenosis owing to ectopic tracheobronchial remnants. J Pediatr Surg 2004; 39: 1183-1187.

10. Solomon AB, Beneck DM. Tracheobronchial Remnants: A Rare Congenital Anomaly. Clin Gastroenterol Hepatol 2011; 9: A26.

11. Kim S-H, Kim H-Y, Jung S-E, et al. Clinical Study of Congenital Esophageal Stenosis: Comparison according to Association of Esophageal Atresia and Tracheoesophageal Fistula. Pediatr Gastroenterol Hepatol Nutr 2017; 20: 79-86.

12. Jeong WS, Jeen YT, Chun HJ, et al. A Case of Congenital Esophageal Stenosis Due to Tracheobronchial Remnants in Adult. Korean J Gastrointest Endosc 2003; 26: 21-25.

13. Saito T, Ise K, Kawahara $\mathrm{Y}$, et al. Congenital esophageal stenosis because of tracheobronchial remnant and treated by circular myectomy: a case report. J Pediatr Surg 2008; 43: 583-585.

14. Olguner M, Ozdemir T, Akgür FM, et al. Congenital esophageal stenosis owing to tracheobronchial remnants: a case report. J Pediatr Surg 1997; 32: 1485-1487.

15. Usui N, Kamata S, Kawahara H, et al. Usefulness of Endoscopic Ultrasonography in the Diagnosis of Congenital Esophageal Stenosis. J Pediatr Surg 2002; 37: 1744-1746.

16. Urushihara N, Nouso H, Yamoto M, et al. Thoracoscopic and laparoscopic esophagoplasty for congenital esophageal stenosis. J Pediatr Surg Case Rep 2013; 1: 434-437. 